\title{
RADIATION DAMAGE IN ICE AT LOW TEMPERATURES STUDIED BY PROTON GHANNELLING
}

\author{
By I. Golecki* and C. JACGARD \\ (Institut de Physique, Université de Neuchâtel, Rue A.-L. Breguet I, CH-20oo Neuchâtel, \\ Switzerland)
}

\begin{abstract}
Ioo keV protons with fluxes between $3 \times 10^{15}$ and $3 \times 10^{16} \mathrm{~m}^{-2} \mathrm{~s}^{-1}$ and in doses up to $4 \times 10^{20}$ $\mathrm{m}^{-2}$ have been used in ice between $-191^{\circ} \mathrm{C}$ and $-87^{\circ} \mathrm{C}$ to create damage and to analyse it. The Rutherford backscattering minimum yield along the $c$-axis (about 0.05 in good monocrystals) increases up to unity with the dose, according to a function which can be scaled by a critical dose depending mainly on temperature (Arrhenius law with activation enthalpy of $0.17 \pm 0.04 \mathrm{eV}$ above $-185^{\circ} \mathrm{C}$ ). Higher flux produces more damage above $-180^{\circ} \mathrm{C}$, but less below. A beam in a random direction is more efficient below $-180^{\circ} \mathrm{C}$, but less at higher temperature than an aligned beam. Beam-induced reordering is observed at definite temperatures and doses. The damage is shown to be due to energy loss by electronic excitations, which decay and produce disordered molecule clusters, mainly by incoherent aggregation of vacancies and interstitials.

RÉsumé. Endommagement causé par les radiations dans la glace à basse température et étudié par canalisation de protons. Des protons de $100 \mathrm{keV}$ avec des flux compris entre $3 \times 10^{15}$ et $3 \times 10^{16} \mathrm{~m}^{-2} \mathrm{~s}^{-1}$ et des doses jusqu'à $4 \times 10^{20} \mathrm{~m}^{-2}$ ont été utilisés dans la glace entre $-191^{\circ} \mathrm{C}$ et $-87^{\circ} \mathrm{C}$ pour créer des dégâts et les analyser. Le rendement minimum de rétrodiffusion de Rutherford le long de l'axe $c$ (environ o,o5 dans de bons monocristaux) augmente jusqu'à l'unité avec la dose, selon une fonction faisant intervenir comme paramètre une dose critique dépendant surtout de la température (loi d'Arrhenius avec une enthalpie d'activation de $0,17 \pm 0,04$ au dessus de $-185^{\circ} \mathrm{C}$ ). Un flux plus élevé produit plus de dégâts au-dessus de $-180^{\circ} \mathrm{C}$, mais moins au-dessous. Un faisceau dans une direction aléatoire est plus efficace au-dessous de $-180^{\circ} \mathrm{C}$, mais l'est moins à des températures supérieures qu'un faisceau aligné. Une réordination induite par le faisceau par observée à des températures et doses bien définies. On montre que les dégâts sont dus aux pertes d'énergie par excitation électronique, donnant lieu à des domaines désordonnés produits surtout par l'agrégation de
lacunes et d'interstitiels.

Zusammenfassung. Strahlungsschäden in Eis bei tiefen Temperaturen, untersucht mittels Protonen-Channeling. $100 \mathrm{keV}$ Protonen mit Flüssen zwischen $3 \times 10^{15}$ und $3 \times 10^{16} \mathrm{~m}^{-2} \mathrm{~s}^{-1}$ und Dosen bis $4 \times 10^{20} \mathrm{~m}^{-2}$ wurden in Eis zwischen $-191^{\circ} \mathrm{C}$ und $-87^{\circ} \mathrm{C}$ benützt, um Strahlungsschäden zu erzeugen und zu analysieren. Das minimale Rutherfordsche Rückstreuungsvermögen entlang der c-Achse (etwa o,o5 in guten Einkristallen) nimmt mit der Dose zu (bis I,o), gemäss einer Funktion, die als Parameter eine kritische Dose enthält, welche hauptsächlich von der Temperatur abhängt (Arrhenius Gesetz mit $0,17 \pm 0,04 \mathrm{eV}$ Aktivierungsenthalpie oberhalb $\left.-185^{\circ} \mathrm{C}\right)$. Ein höherer Fluss erzeugt mehr Schäden oberhalb $-180^{\circ} \mathrm{C}$, aber weniger unterhalb dieser Temperatur. Ein Strahl mit Zufallsrichtung ist unter $-180^{\circ} \mathrm{C}$ wirksamer als ein gerichteter Strahl, aber weniger bei höheren Temperaturen. Eine vom Strahl induzierte Unordnung wird bei wohl bestimmten Dosen und Temperaturen beobachtet. Die Schäden rühren von dem durch elektronische Anregungen verursachten Energie-Verlust her. Sie bestehen aus ungeordneten Bezirken, welche hauptsächlich durch Agregation von Leerstellen und Zwischengittermolekülen entstehen.
\end{abstract}

\section{Introduction}

For several decades considerable interest has been devoted to the radiation damage produced by energetic particles in solids, not only from the point of view of technological applications (e.g. nuclear power) but also in order to assess the effect of nuclear technology or of outer-space conditions on animate and inanimate matter. Although the damage mechanisms are complex, significant analogies can be found in quite different materials.

We have been prompted to study the damaging which $100 \mathrm{keV}$ protons cause in ice in the course of an investigation into the channelling of the surface structure of ice monocrystals (Huber and others, 1972, 1973; Huber, unpublished). For details of the method the reader is referred to a comprehensive review of Gemmell (1974). Briefly, one measures the backscattering yield $\chi$ of a well-collimated proton beam incident on the crystal. The yield is normalized to unity for the beam in a random direction, and drops to a few per cent when the * Present address: Department of Electrical Engineering I I 6-8 I, California Institute of Technology, Pasadena,
CA 9 1 1 25, U.S.A. 
beam is parallel to a principal crystallographic axis. Disorder, such as thermal vibrations, interstitials, or amorphous zones, shows up as an increase in the yield. The principal advantages of using $100 \mathrm{keV}$ as opposed to higher energies in the case of ice are:

(I) The stopping power has a flat maximum at $100 \mathrm{keV}$ (Whaling, 1958), and thus the depth resolution is at a maximum too.

(2) The stopping power is the same for an aligned and for a random beam, simplifying the data evaluation.

(3) The yield and "signal/damage" ratio are higher, since the Rutherford backscattering cross-section is inversely proportional to (energy) ${ }^{2}$.

In previous experiments, Huber (unpublished) found that the sensitivity to damage increased rapidly below $-150^{\circ} \mathrm{C}$. At $-143^{\circ} \mathrm{C}$, a dose of one proton per channel (parallel to the $a$-axis) increased the yield by less than $\mathrm{I} \%$, whereas at $-170^{\circ} \mathrm{C}$ one-fifth of this dose brought the yield near unity, indicating a complete loss of long-range order in the surface layer considered (thickness $240 \mathrm{~nm}$ ). The temperature domain of this abrupt change coincides with other anomalies observed in the dielectric constant (Dengel and others, 1964), the protonic mobility (Eckener and others, 1973), the sound velocity (Helmreich and Bullemer, I 969), the specific heat (Matsuo and others, I973), and even the scattering of $\gamma$-rays (Fitzgerald and O'Connor, 1976). The region is also critical for the "amorphous-cubic" transition, and for vapour deposition on monocrystals; the deposited layer is coherent with the substrate only above $-150^{\circ} \mathrm{C}$ (Huber, unpublished). The possible relationship of all these effects with the damage sensitivity, and the question of a beam-induced phase transition versus a thermallyactivated process suggested a closer look at the damage formation in this temperature range. In this paper, we present some experimental details (Section 2) and the results of the measurements (Section 3). A tentative kinetic model, which is supported by the measurements, is discussed in Section 4 .

\section{Experimental details}

The experimental apparatus, with the exception of several improvements, has been described in detail by Huber (unpublished). The $100 \mathrm{keV}$, one millimetre diameter proton beam is collimated by the ion optics to $0.05^{\circ}$. The scattering chamber is evacuated by means of a turbo-molecular pump (Leybold-Heraeus, rating $350 \mathrm{l} / \mathrm{s}$ ) to a hydrocarbon-free vacuum of $1^{-6}$ Torr $\left(1.33 \times 10^{-4} \mathrm{~Pa}\right)$. A $500 \mathrm{~cm}^{2}$, liquid-nitrogen-cooled copper trap serves to depress the partial pressure of water vapour to $2 \times \mathrm{IO}^{-9}$ Torr $\left(2.66 \times \mathrm{IO}^{-7} \mathrm{~Pa}\right)$, equivalent to a dew point of $-133^{\circ} \mathrm{C}$. Thus the water-vapour condensation rate on a sample maintained at - $19 \mathrm{I}^{\circ} \mathrm{C}$ is smaller than 3 monolayers/h. The top flange of the scattering chamber accommodates a goniometer, on which is mounted a variable-temperature cryostat. The goniometer has four degrees of freedom: rotation $\left(360^{\circ}\right.$, precision $\left.0.05^{\circ}\right)$, tilt $\left( \pm 10^{\circ}, 0.025^{\circ}\right)$, vertical and horizontal translation ( $20 \mathrm{~mm}, 0.01 \mathrm{~mm}$, and $12 \mathrm{~mm}, 0.005 \mathrm{~mm}$, respectively). The rotation and tilt axes cross one another at the surface of the sample. The cryostat which is cooled by liquid nitrogen, operates by gas exchange. The lowest temperature possible is $-19 \mathrm{I}^{\circ} \mathrm{C}$, and stable operation is possible up to room temperature.

The beam intensity is measured by intercepting part of it on a "Micromesh" nickel grid (E.M.I. Electronics Ltd), of cell side $0.125 \mathrm{~mm}$ and $75 \%$ transmission. The positively-biased grid, located at the entrance to the scattering chamber, is connected to a model 602 Keithley electrometer, the analogue output of which controls data acquisition. A second nickel grid, of cell side $0.013 \mathrm{~mm}$ and $30 \%$ transmission is placed on a mobile mount $20 \mathrm{~mm}$ in front of the insulating ice sample. Low-energy secondary electrons emitted by the negatively-biased grid under proton irradiation serve to neutralize the positive charge carried by the proton beam to the surface of the sample. This grid has only negligible effect on beam divergence and 
energy profile; no sputtering of nickel atoms has ever been observed. The mobile mount also carries a pre-aligned, $0.28 \mathrm{~mm}$ diameter diaphragm which can be used to reduce the beam spot on the crystal. The back-scattered protons are detected at $150^{\circ}$ by means of a $25 \mathrm{~mm}^{2}$ silicon surface-barrier detector (Ortec Premium) connected to standard spectroscopy electronics. The overall resolution with the detector cooled to $193 \pm 5 \mathrm{~K}$ is $3 \mathrm{keV}$, corresponding to a depth resolution in ice of $\mathrm{I} 6 \mathrm{~nm}$. The system energy calibration is done by scattering off a thin target of xenon or krypton gas at $\mathrm{IO}^{-2}$ Torr $(\mathrm{I} .3 \mathrm{~Pa})$, and can be checked with the aid of a $\mathrm{I} \mathrm{nm}$ evaporated layer of gold on a beryllium substrate.

The pure, single-crystal ice samples, typically $5 \mathrm{~mm}$ on a side, are cut on a refrigerated lathe from a larger oriented crystal (kindly provided by Dr J. H. Bilgram, ETH, Zürich). The surface of the crystal is cleaned in situ prior to measurement by means of $3 \mathrm{keV}$ xenon- or krypton-ion sputtering combined with sublimation at $-80^{\circ} \mathrm{C}$. The $2 \mathrm{~mm}$ diameter heavy-ion beam has an intensity of a few $\mu \mathrm{A} / \mathrm{cm}^{2}$. The proton irradiations are performed both along the $c$-axis (aligned direction) and $9^{\circ}$ off the $c$-axis (random direction). Irradiations in the temperature range $-\mathrm{I}^{1} \mathrm{I}^{\circ} \mathrm{C}$ to $-\mathrm{I}_{4} 0^{\circ} \mathrm{C}$ have been carried out with fluxes of $3 \times \mathrm{IO}^{\mathrm{II}}$ and $3 \times 1 \mathrm{O}^{12}$ $\mathrm{H}^{+} / \mathrm{cm}^{2}$ s (low and high flux, respectively) up to a dose of $4 \times 10^{16} \mathrm{H}^{+} / \mathrm{cm}^{2}$ or $70 \mathrm{H}^{+} / \mathrm{channel}$ (this corresponds to $5 \times 10^{11} \mathrm{rad}$ ). Some measurements have been extended to $-87^{\circ} \mathrm{C}$ with a flux of $5 \times \mathrm{IO}^{13} \mathrm{H}^{+} / \mathrm{cm}^{2} \mathrm{~s}$ up to $\mathrm{I}_{50} \mathrm{H}^{+} /$channel $\left(\approx \mathrm{IO}^{12} \mathrm{rad}\right)$. The crystal temperature is measured with a calibrated copper-constantan thermocouple.

The principal quantity measured as a function of dose is the minimum yield $\chi$ along the $c$-axis in a layer between 20 and $60 \mathrm{~nm}$ beneath the surface. In addition, back-scattered energy spectra and angular scans are taken at various stages of the damage process. The known stopping power of protons in $\mathrm{H}_{2} \mathrm{O}$ (Whaling, r 95 8 ), $\mathrm{d} E / \mathrm{d} x=84.6 \pm 8 \mathrm{eV} / \mathrm{nm}$, is used to determine the energy-depth scale. Special care is needed for the measurement of the damage caused during random irradiations. In order to ensure that the minimum yield is measured exactly at the I mm diameter irradiated area, the surface of the crystal is scanned with a $0.28 \mathrm{~mm}$ diameter beam by shifting the cryostat assembly.

\section{Results}

\subsection{Aligned irradiations: $-191^{\circ} \mathrm{C} \leqslant T \leqslant-140^{\circ} \mathrm{C}$}

The effect of radiation damage on the channelling dip (Fig. I) is mainly to increase the minimum yield above the undamaged value of about 0.05 , the full-width at half-maximum (fwhm) being only slightly reduced from $2.0^{\circ}$ to $1.8^{\circ}$. At high dose, the channelling effect disappears altogether (i.e. $\chi=\mathrm{I}$ ), indicating either amorphization of the measured zone, or possibly a structure consisting of misaligned microcrystals. The exact nature of the defects can rarely be determined by channelling alone (see Quéré, 1976). In a typical sequence of back-scattered energy spectra, the surface peak increases with dose, indicating the formation and progression of a disordered region from the surface of the crystal inwards. The aligned and random spectra eventually merge when long-range order has been lost.

The variation of the damage curves $\chi(D)$ with temperature $T$ and proton flux $\mathcal{J}$ is illustrated in Figure 2 for aligned irradiations. For fixed $T$ and $\mathcal{Z}$, the minimum yield increases with dose, tending asymptotically to a saturation value of unity. On a linear dose scale, and at $T \leqslant-180^{\circ} \mathrm{C}$, the curves have an exponential form (slope at the origin positive and maximum), while at higher temperatures they exhibit a sigmoid character, that is, nearly zero slope at the origin, followed by an inflection point for $\chi<0.5$. An inflection point may exist even below $-180^{\circ} \mathrm{C}$ at an immeasurably small dose. The temperature independence of the saturation value, as seen in particular in Figure 3 (discussed below), indicates that in the temperature range studied the irradiated region can always be amorphized completely. However, the measurements at $T \geqslant-156^{\circ} \mathrm{C}$ were not taken to saturation, in order to avoid gross macroscopical damage effects (e.g. blistering, bubble formation, radiation-induced 
stress, and sputtering; for the doses used in this study, separate measurements on ice films deposited on a gold-on-beryllium target showed sputtering to be entirely negligible). The exact saturation value of $\chi$ depends on the choice of the random direction (Ziegler and Crowder, 1972), and therefore a $10 \%$ deviation about unity can be tolerated if the aligned spectrum has all the features of a random one. The dependence on the proton flux is such that at $T \geqslant-172^{\circ} \mathrm{C}$ the high flux produces much more damage than the low flux, but near

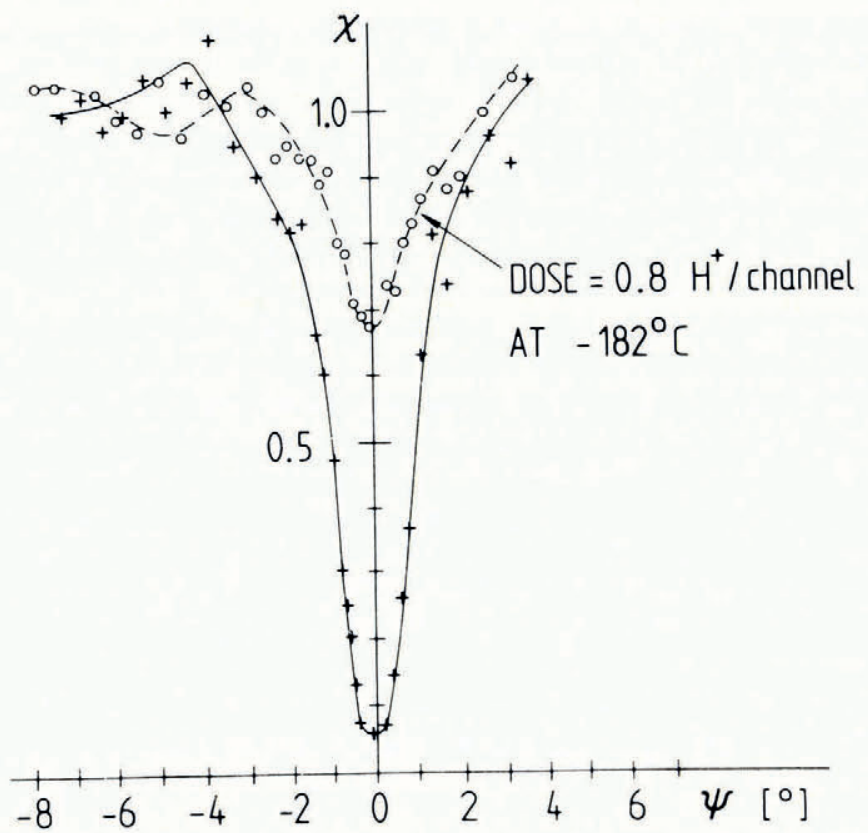

Fig. I. Angular dependence of the channelling yield along the c-axis in ice. The solid curve was measured on a freshly cleaned surface at $-140^{\circ} \mathrm{C}\left(\right.$ fwhm $\left.=2^{\circ}\right)$. The dashed curve was measured at $-15 I^{\circ} \mathrm{C}$ on an area previously irradiated with $0.8 \mathrm{H}^{+} /$channel in the random direction at $-182^{\circ} \mathrm{C}\left(\right.$ fwhm $\left.=2 \times 0.9^{\circ}\right)$. In both cases the scattering zone beneath the surface was $40 \mathrm{~nm}$ thick.

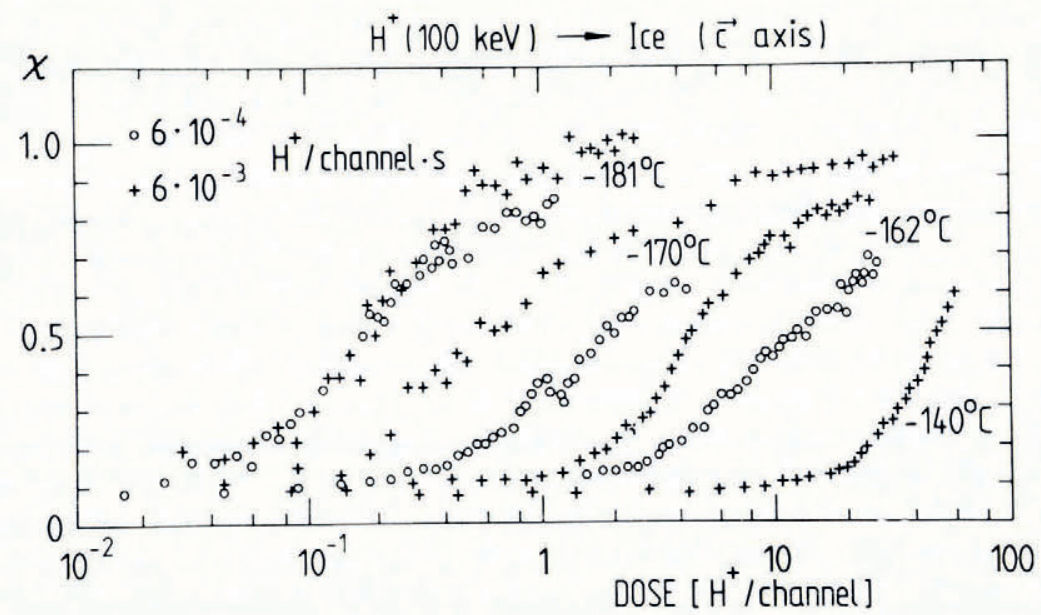

Fig. 2. Dose dependence of minimum yield in ice for aligned irradiations, measured in a 40 nm thick layer beneath the surface. I $\mathrm{H}^{+} /$channel $=5.7 \times 10^{14} \mathrm{H}^{+} / \mathrm{cm}^{2}$. 
$-\mathrm{I} 8 \mathrm{I}^{\circ} \mathrm{C}$, this dose-rate effect disappears, and is then even reversed at $-\mathrm{I} 9 \mathrm{I}^{\circ} \mathrm{C}$. This behaviour led us to look for an annealing of the damage by monitoring the minimum yield as a function of time and temperature for crystal areas previously damaged to various levels. No purely thermal annealing could be observed for $T \leqslant-140^{\circ} \mathrm{C}$ over a period of one day (at $T>-133^{\circ} \mathrm{C}$, the crystal surface evaporates slowly, thus ruling out any long-term measurements). Therefore, any recovery effects must be attributed to the beam itself.

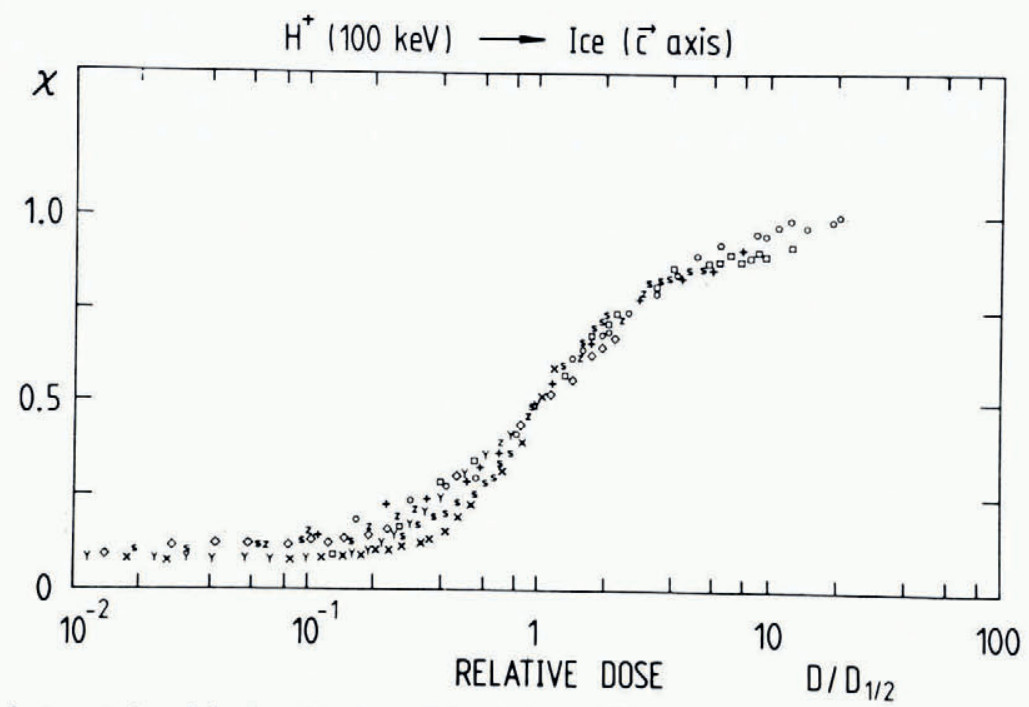

Fig. 3. Reduced representation of the dose dependence of the minimum yield in ice, where $D_{\mathrm{t} / 2}=D(\chi=0.5) . \square:-191^{\circ} \mathrm{C}$, $\mathrm{f}_{2} ;+:-181^{\circ} \mathrm{C}, \mathcal{J}_{1} ; 0:-17 I^{\circ} \mathrm{C}, \mathcal{J}_{2} ; \mathrm{Z}:-17 I^{\circ} \mathrm{C}, \mathcal{J}_{1} ; \mathrm{S}:-162^{\circ} \mathrm{C}, \mathcal{J}_{2} ; \diamond:-162^{\circ} \mathrm{C}, \mathcal{J}_{1} ; \mathrm{Y}:-150^{\circ} \mathrm{C}, \mathcal{J}_{2}$; $\mathrm{X}:-\mathrm{I} 4 \mathrm{O}^{\circ} \mathrm{C}, \mathrm{f}_{2}$. $\mathrm{f}_{2}$ and $\mathcal{F}_{1}$ denote a proton flux of $3 \times \mathrm{IO}^{12}$ and $3 \times \mathrm{IO}^{\mathrm{I1}} \mathrm{H}^{+} / \mathrm{cm}^{2}$ s, respectively. The curves have been smoothed for clarity.

In an effort to identify common features of the damage curves, we observed that they could be superimposed on each other merely by a shift of the logarithmic dose scale (see Fig. 3), thus suggesting the existence of a single relevant parameter $D_{c}=D_{c}(T, \mathcal{F})$. In fact, this picture is somewhat oversimplified, since the reduced representation actually results in a family of curves, which intersect at $\chi=0.5$ because of the arbitrary definition of $D_{c}$. The nature of the temperature dependence of this characteristic dose $D_{c}$ can be examined by plotting $\log D_{0.5}$ or, alternatively, $\log (\mathrm{d} \chi / \mathrm{d} D)_{\max }$ (the maximum value of the slope) versus inverse temperature, as shown in Figure 4. In spite of some scatter in the experimental results, a visual inspection indicates that an Arrhenius plot is appropriate for $T \geqslant-182^{\circ} \mathrm{C}$ $\left(\geqslant-176^{\circ} \mathrm{C}\right)$ for low (high) flux irradiations, while at lower temperatures the $T$-dependence is seen clearly to weaken. The respective enthalpies, $\Delta H$ (low flux) $=0.16 \pm 0.04 \mathrm{eV}$, $\Delta H$ (high flux) $=0.20 \pm 0.05 \mathrm{eV}$, were obtained by least-squares fits, and were verified to be significantly different by means of the usual statistical tests. The $D_{0.5}$ plots yielded the set of values $\Delta H$ (low flux) $=0.13 \pm 0.04 \mathrm{eV}$ and $\Delta H$ (high flux) $=0.2 \mathrm{I} \pm 0.06 \mathrm{eV}$, which is statistically compatible with the previous set. These results, and especially the dose-rate dependence of $\Delta H$, substantiate the existence of a radiation-assisted, thermally-activated annealing process alluded to above.

Two additional effects, which were observed only when substantial damage had been done (i.e. for $\chi \gtrsim 0.5$ ), were fluctuations in the minimum yield which were larger than expected from the statistics alone, and a series of sudden drops in $\chi$ occurring at reproducible dose values, as seen in the $-\mathrm{I}_{70}{ }^{\circ} \mathrm{C}$ curve (low flux) in Figure 2 at $\mathrm{I}_{\mathrm{H}} \mathrm{H}^{+} /$channel. A plot of $\log D_{\mathrm{I}}$, 
the dose at which the first drop occurred, versus inverse temperature yielded a straight line with an enthalpy of $\Delta H=0.1 \mathrm{I} \pm 0.03 \mathrm{eV}$, for both high and low flux, although the drops occurred at higher dose values in the high-flux case. Similar effects have been reported for the alkali halides (Hollis, I973), in $\mathrm{BaTiO}_{3}$ (Gemmell and Mikkelson, 1972), and in Ge (Holmén and Högberg, r972), but to our knowledge this is the first time that a thermallyactivated process has been shown to take place. In agreement with Hollis (1973), we believe that these effects are due to beam-induced re-arrangement of displaced defects in the lattice. For instance, a clustering of interstitials may reduce $\chi$ by emptying some of the channels previously blocked by the same interstitials. The hypothesis that non-neutralized positive charge in the bulk may be the cause of these effects was countered by making measurements of sub-surface potential in the ice crystal during irradiation using an electrostatic voltmeter.

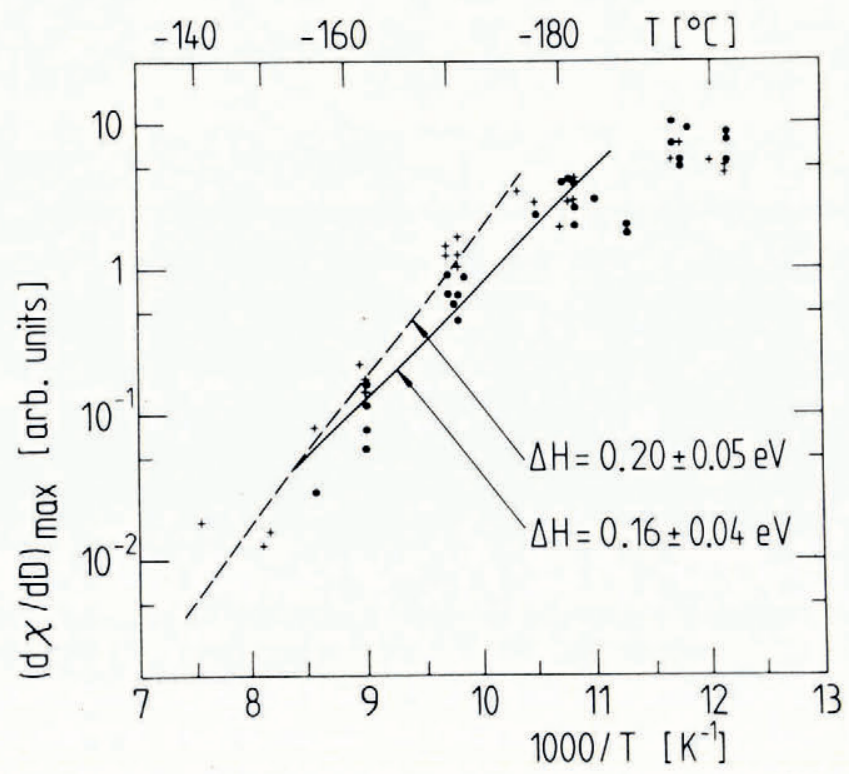

Fig. 4. Temperature dependence of the maximum slope of the damage curves. Crosses refer to high proton flux, solid circles to low proton flux.

3.2. Random irradiations: $-191^{\circ} \mathrm{C} \leqslant T \leqslant-140^{\circ} \mathrm{C}$

For the measurement of damage caused in random irradiations, care had to be taken in order to avoid additional damage or annealing by the measuring beam. To this end the following procedure was adopted: For each $(T, \mathcal{F})$ set, two series of irradiations were carried out with various doses at different but equivalent points on the crystal surface: one series in the random direction, and an identical series in the aligned direction. The minimum yield was then measured at $T \approx-{ }^{1} 55^{\circ} \mathrm{C}$ with a small enough dose to avoid further damage. This method proved quite reliable after comparison with the known damage level in the aligned irradiations, but did not yield such detailed damage curves as did the damage-level results. Nevertheless, the following conclusions were drawn: At $T \leqslant-180^{\circ} \mathrm{C}$, random irradiation produced slightly more damage than aligned irradiation, but at higher temperatures this trend was reversed; at $T=-162^{\circ} \mathrm{C}$ the damage caused by random irradiation was only half as large as that caused by aligned irradiation. This temperature dependence obtained for both low and high flux, thus indicating a dose-rate effect similar to that in aligned 
irradiations. No definite conclusion could be reached regarding the re-arrangement effect because of the relatively small number of dose values per curve. Angular scans showed a similar shape as in aligned irradiations.

\subsection{Aligned irradiations: $-130^{\circ} \mathrm{C} \leqslant T \leqslant-87^{\circ} \mathrm{C}$}

In order to avoid sublimation of the surface during measurement, the crystal was kept in equilibrium with its own vapour in a special chamber (Golecki and Jaccard, in press) fixed inside the large scattering chamber. The results obtained at $-130^{\circ} \mathrm{C}$ were similar to those previously described for lower temperatures. However, for $T \geqslant-\mathrm{II} 5^{\circ} \mathrm{C}$, a remarkable change in behaviour was observed to take place. The surface peak in the back-scattered energy spectra disappeared with increasing dose, as the high-energy edge became rounded off. Furthermore, the sensitivity to radiation damage increased rapidly with temperature, unlike the observations made at $T \leqslant-130^{\circ} \mathrm{C}$. The shape of the damage curves was sigmoid, and the re-arrangement phenomenon was also observed in this temperature range. Initial analysis of the results yielded an activation enthalpy of about $0.4 \mathrm{eV}$. These observations indicate that a completely different damage mechanism operates in this temperature region, which includes the measurements previously reported by Huber and others (1972). Probably the different behaviour should be attributed to different annealing and clustering properties of the defects in ice. A similar temperature dependence has been reported for silicon by Pabst and Palmer [1975].

\section{Discussion}

The most conspicuous characteristic of the damage production is the occurrence of a "scaling law" with temperature as a parameter in collaboration with the critical dose. According to phenomenological calculations, the heat conductivity dissipates the proton energy in such a way that the surface-temperature rise at the beam impact is smaller than o. I deg. Thus the bulk temperature can be assumed to be relevant. The fact that the temperature dependence is continuous, with an Arrhenius behaviour over a large range, denies any phase-transition mechanism; it shows that near the surface, the local temperature is not influenced significantly by the beam. There are certainly "thermal spikes", but the essential features of the disorder-producing mechanism occur quite near the bulk temperature in a medium which is far from chemical equilibrium but nearly homogeneous.

The proton energy loss of $85 \mathrm{eV} / \mathrm{nm}$ at the surface is due mainly to electronic excitation. Elastic collisions with oxygen nuclei account for less than one per cent of the loss, nevertheless, the ability of the collision process to displace molecules has to be examined. An interstitialvacancy pair requires at least $\mathrm{I} \mathrm{eV}$ (to break four hydrogen bonds) and standard formulae (Nelson, I968) give a cross-section for $100 \mathrm{keV}$ protons of $\sigma_{d}=5 \times 10^{-23} \mathrm{~m}^{2}$ for an energy transfer greater than this energy. If secondary collisions are taken into account, this value is increased at most by a factor of ten, up to $5 \times 10^{-22} \mathrm{~m}^{2}$. If the dose $D$ is expressed in protons per channel, with the channel area $F_{\mathrm{c}}=\mathrm{I} .75 \times 1 \mathrm{IO}^{-19} \mathrm{~m}^{2}$, the maximum relative concentration of interstitials amounts then to $c_{\mathrm{i}}=D \sigma_{d} / F_{\mathrm{c}} \approx 3 \times 10^{-3} D$, which is nearly equal to the increase of the yield $\Delta \chi$ provided $\chi \ll \mathrm{I}$ and without thermal damage restoration, i.e. at a low temperature. At $-\mathrm{r} 8 \mathrm{o}^{\circ} \mathrm{C}$, the measurements give for the disorder growth rate $\mathrm{d} \chi / \mathrm{d} D=4$ (proton/channel) ${ }^{-1}$. The result of the calculation above lies three orders of magnitude lower, indicating that the observed disorder is not produced by direct nuclear collisions in ice. It has to be the result of the electronic excitation, which makes up almost the total energy loss.

The mechanism can be viewed as having three steps. First, the molecules are ionized and the electrons are shot into the conduction band where they excite secondary electrons, dispersing their energy around the trajectory of the incident proton. Hydrogen and $\mathrm{OH}$ 
bonds are ruptured, $\mathrm{H}$ and $\mathrm{OH}$ radicals are formed, as well as ions $\left(\mathrm{OH}^{-}, \mathrm{H}_{3} \mathrm{O}^{+}\right.$, etc. $)$. All these species interact by many different reactions, the ions are neutralized rapidly by mobile electrons and holes, and the free radicals which are mobile above $-180^{\circ} \mathrm{C}$ (Eldrup, 1976), recombine also. The result of all these processes is, as a second step, the creation of several types of defects (vacancies, interstitial molecules, chemical compounds such as $\mathrm{H}_{2}, \mathrm{H}_{2} \mathrm{O}_{2}$, etc.). Nuclear displacements happen either by a multiple ionization process (Varley, 1962) or by de-excitation of trapped excitons (Itoh, 1976), a bimolecular species being violently separated in both cases and thus providing the necessary momentum. Since the vacancies are mobile above $-175^{\circ} \mathrm{C}$ (Eldrup, 1976) with an activation enthalpy of $0.34 \pm 0.07 \mathrm{eV}$, the defects should also be mobile in this temperature range.

In the present case, channelling is sensitive to oxygen nuclei which have been displaced perpendicular to the $c$-axis by at least their Thomas-Fermi radius ( $0.02 \mathrm{~nm}$ ). Protons need not be considered; they are not detected at $150^{\circ}$ back-scattering and their cross-section for dechannelling is quite small. The temperature dependence of the damage formation suggests that the chemical reaction products (e.g. $\mathrm{H}_{2} \mathrm{O}_{2}$ ) are irrelevant for the following reasons. If they are created during the thermal spikes their formation is temperature independent, and if they are produced by a diffusive motion of the free radicals after the thermal spikes their concentration should grow with the temperature. This disagrees with the observed decrease of damage rate with increasing temperature. On the other hand, their production by the beam could be balanced by their diffusion towards the surface, giving the correct temperature dependence. However, this diffusion should also occur without beam, that is, the damage should anneal, and this also contradicts the observations; once created, the damage does not anneal at temperatures less than $-130^{\circ} \mathrm{C}$. This last point, together with the fact that the relative concentration of the displaced oxygen atoms can be quite high (up to unity) if $\chi \approx \mathrm{I}$, can be accounted for by damage which consists of clusters of molecules, either amorphous (below $-150^{\circ} \mathrm{C}$ ) or crystallized, but not coherent with the original lattice. If they contain at least four or five molecules, these clusters are stable in respect of thermal activation, that is, interstitials or vacancies cannot "evaporate" from them.

The third step of the damage mechanism is thus the formation of these clusters. A process which generates them in a single event and which shows the correct temperature dependence is difficult to envisage. We suggest rather that they build up molecule by molecule. This can occur by the successive aggregation of vacancies and interstitial $\mathrm{H}_{2} \mathrm{O}$ molecules which are produced in sufficient number near each proton trajectory and which diffuse freely after the thermal spike has dissipated, even at low temperatures, since their paths are quite short. Then, the temperature dependence of the critical dose does not reside in the diffusion but in the probability that each interstitial molecule trapped in a void on the surface of a cluster will bind with the cluster instead of binding in an ordered way with the surrounding lattice.

This process is very improbable if the interstitial is trapped in a single vacancy since it can be gripped there by all four bonds together and forced to occupy a lattice site. If, on the other hand, it is trapped by a vacancy aggregate, it can be gripped only by one bond (or two) and it is quite possible that it takes a "wrong" place with respect to the lattice, especially when a second interstitial is also trapped within a short time, thus binding the first one and stabilizing it. Vacancy aggregates have been postulated by Eldrup (1976), who mentions voids up to I. $5 \mathrm{~nm}$ diameter, and by Unwin and Muguruma (1972). Their creation can be explained by the attractive interaction between the vacancies, due to unsaturated H-bonds on the void surface. The elastic potential gives also an attraction between vacancies and interstitials, but a repulsion between interstitials. Therefore, the latter do not aggregate, but are trapped by the vacancy clusters, which become filled up and thus cannot reach a very large size due to the high interstitial concentration.

The possibility of disordered agglomeration of interstitials in vacancy clusters is substantiated by the observation by Huber (unpublished) of non-coherent deposition of vapour 
on the crystal surface below $-150^{\circ} \mathrm{C}$. Above this temperature the domain structure is possibly cubic but strongly distorted, and is anyway non-coherent with the matrix. At lower temperatures, there is no experimental indication of order and the structure is certainly amorphous.

According to the measurements, the damage does not depend only on the properly reduced dose, but also on the proton flux. This implies that damage growth is not simply proportional to a reaction coefficient which depends on temperature, but that it is the result of chain reactions between isolated vacancies, vacancy clusters, disorerded domains, and interstitials.

It is quite possible to write down a system of simultaneous differential equations which describe the formation and the growth of the disordered domains, and which involve the concentration of all the filled and empty multivacancies. However, this introduces a large number of kinetic parameters (the reaction coefficients) which are unknown and which cannot be determined from the measurements. Therefore, such a complicated calculation has no meaning in the present status of experiment and we develop a simple semi-quantitative model instead. We assume that the concentration of the interstitials is constant, that is, those produced by the beam are continuously added to the disordered domains. If $f$ is the flux (in $\mathrm{m}^{-2} \mathrm{~s}^{-1}$ ) and $k$ is a coefficient for the defect yield (in $\mathrm{m}^{-1}$ ), the beam then creates $k \mathcal{F}$ defects per unit time and volume. Since these have a meaning only in the ordered lattice, we introduce the disordered volume fraction $X$ which can be equated as a first approximation to the minimum yield $\chi$. The average rate of interstitial production is therefore $k f(1-X)$. In order to describe the time dependence of $X$, one has to introduce the probability $P$ that an interstitial entering a disordered domain takes a "wrong" position with respect to the lattice. If $v_{0}$ is the molecular volume $\left(3 \times 10^{-29} \mathrm{~m}^{3}\right)$, we have then

$$
\frac{\mathrm{d} X}{\mathrm{~d} t}=v_{0} k \mathcal{F}(\mathrm{r}-X) P,
$$

or with the dose $D=\mathcal{F t}$

$$
\frac{\mathrm{d} X}{\mathrm{~d} D}=(\mathbf{I}-X) v_{0} k P .
$$

From the measurements, we infer that $P$ has the form

$$
P=P_{0} /(\mathbf{I}+b \exp (-\Delta H / k T)) \text {. }
$$

$\Delta H$ could mean the potential step which has to be climbed over by a molecule in order to turn from a "wrong" to a "correct" position. At low temperatures $\left(-\mathrm{I} 80^{\circ} \mathrm{C}\right), P=P_{0}$, $X$ grows as $\mathrm{I}-\exp \left(-D / D_{c}\right)$, with $D_{c}$ independent of $\mathcal{J}$ and $T$; there is no inflexion point. At higher temperatures $P$ and $D_{c}$ depend on $T$, and $0.13 \mathrm{eV}<\Delta H<0.2 \mathrm{I} \mathrm{eV}$. At the beginning of the process $\left(D \ll D_{c}\right)$, the small aggregates predominate, i.e. $b$ is larger and $P$ is smaller than at higher dose. This accounts for the presence of the inflexion point.

The dependence on $\mathcal{f}$ can be explained in the following way. If $\mathcal{f}$ is large, the instantaneous interstitial concentration is large too and the time between the aggregation of an interstitial in a disordered domain and the aggregation of the next one is short. This increases the probability that the molecules are blocked in a "wrong" position. have

The product $k P_{0}$ can be evaluated from the measurements. At $-180^{\circ} \mathrm{C}$ for $X \leqslant \mathrm{r}$, we

$$
\frac{\mathrm{d} X}{\mathrm{~d} D}=4(\text { proton } / \text { channel })^{-1}=7 \times 10^{-19} \mathrm{~m}^{2} .
$$

Then

$$
k P_{0}=\frac{\mathrm{d} X}{\mathrm{~d} D} / v_{0}=2 \times 10^{10} \mathrm{~m}^{-1}=20 \mathrm{~nm}^{-1} .
$$


With inelastic losses amounting to $S=85 \mathrm{eV} / \mathrm{nm}$, the energy $E_{0}$ per displaced oxygen atom is given by $E_{0}=S / k \approx P_{0} \times 4 \mathrm{eV}$. Even if we assume that $P_{0} \approx \mathrm{I}$, the energy necessary to produce a Frenkel pair is larger than $E_{\mathrm{o}}$ because the number of displaced oxygen atoms is certainly larger than the number of clustered molecules; each cluster is surrounded by a strain field, and if the cluster size is not too large, the volume of the observable perturbed zone can be at least twice the cluster volume. One has, in any event, to expect a Frenkel-pair yield smaller than in other substances for the following reasons. First, these measurements pertain to a highly perturbed lattice, the strength of which can be significantly reduced. Secondly, Frenkel-pair formation does not imply electric charge separation as in ionic crystals, and the hydrogen bond is relatively weak. In covalently-bonded crystals, such as silicon (Pabst and Palmer, [1975]), sapphire, or quartz (Krefft and others, 1975), the damage results only from the elastic nuclear collisions, the sensitivity being reduced by $10^{3}$ to $10^{4}$ with respect to ice. Comparison with other physico-chemical studies (Eldrup, 1976; Buxton and others, 1977) is difficult because the radiation doses used in this work (between Grad and Trad) are higher by several orders of magnitude and the crystal structure is severely perturbed.

\section{Conclusion}

The damage produced in ice $40 \mathrm{~nm}$ beneath the surface between -190 and $-140^{\circ} \mathrm{C}$ by high-energy protons consists of the displacement of oxygen atoms and can be revealed by means of proton channelling. This disorder is not the result of direct collisions but of a large number of fast chemical reactions initiated by the strong electronic excitation diffusing from the proton trajectories and leading to the homogeneous creation of point defects (vacancies, interstitials, $\mathrm{H}_{2}, \mathrm{H}_{2} \mathrm{O}_{2}$, etc.). The motion of these defects is thermally activated, and assisted at low temperature by the elastic deformation potential. They aggregate and build up domains which are disordered with respect to the lattice. Within these domains the structure is certainly amorphous below $-150^{\circ} \mathrm{C}$, and possibly has cubic short-range order above this temperature. The probability that aggregated molecules are bound incoherently to the lattice is a decreasing function of temperature which appears in the behaviour at the critical dose. The disorder cannot anneal in the considered temperature range. More information could be obtained from experiments performed under other conditions, such as heavier projectiles $\left(\mathrm{He}^{+}\right)$, higher energies (some $\mathrm{MeV}$ ), and by other surface investigation methods (LEED) which are sensitive to disorder.

\section{Acknowledgements}

The participation of F. Rudolf at the early stages of this project is acknowledged. This work was supported by the Schweizerischer Nationalfonds zur Förderung der wissenschaftlichen Forschung. It forms part of the thesis to be submitted by I. Golecki to the Faculté des Sciences, Université de Neuchâtel, in partial fulfilment of the requirements for the degree of Ph.D. in Physics.

\section{REFERENCES}

Buxton, G. V., and others. I977. Two types of localized excess electrons in crystalline $\mathrm{D}_{2} \mathrm{O}$ ice, [by] G. V. Buxton, H. A. Gillis and N. V. Klassen. Canadian Journal of Chemistry, Vol. 55, No. 12, p. 2385-95.

Dengel, O., and others. 1964 . Ferroelectric behaviour of ice, [by] O. Dengel, U. Eckener, H. Plitz and N. Riehl. Physics Letters, Vol. 9, No. 4, p. 291-92.

Eckener, U., and others. I973. Transit time measurements of protons in ice, [by] U. Eckener, D. Helmreich and H. Engelhardt. (In Whalley, E., and others, ed. Physics and chemistry of ice: papers presented at the Symposium on the Physics and Chemistry of Ice, held in Ottawa, Canada, I4-18 August 1972. Edited by E. Whalley, S. J. Jones, L. W. Gold. Ottawa, Royal Society of Canada, p. 242-45.)

Eldrup, M. I976. Vacancy migration and void formation in $\gamma$-irradiated ice. Journal of Chemical Physics, Vol. 64, No. 12, p. $5283-90$. 
Fitzgerald, W. J., and O'Connor, D. A. 1976. Anomalies in the scattering of gamma-rays from single crystals of HF-doped ice- $I_{h}$ around $100 \mathrm{~K}$. Zeitschrift für Physik, B, Vol. 24, No. 1, p. I-5.

Gemmell, D. S. 1974. Channeling and related effects in the motion of charged particles through solids. Review of Modern Physics, Vol. 46, No. 1, p. 129-227.

Gemmell, D. S., and Mikkelson, R. C. 1972. Channeling of protons in thin $\mathrm{BaTiO}_{3}$ crystals at temperatures above and below the ferroelectric Curie point. Physical Review, Sect. B, Vol. 6, No. 5, p. 161 3-35.

Golecki, I., and Jaccard, C. In press. An apparatus for channeling experiments at Torr pressures. Nuclear Instruments and Methods.

Helmreich, D., and Bullemer, B. 1969. Anomales elastisches Verhalten von Eis bei tiefen Temperaturen. Physik der kondensierten Materie, Bd. 8, Ht. 5, p. 384-92.

Hollis, M. J. 1973. Channeling of $1-\mathrm{MeV} \mathrm{He}^{+}$ions in $\mathrm{NaCl}$ : damage and temperature effects. Physical Review, Sect. B, Vol. 8, No. 3, p. $93 \mathrm{I}^{-}-35$.

Holmén, G., and Högberg, P. 1972. A study of the production and removal of radiation defects in Ge using secondary electron emission. Radiation Effects, Vol. 12, Nos. 1-2, p. 77-85.

Huber, $H$. Unpublished. Application de la canalisation de protons de $100 \mathrm{keV}$ à l'étude de la structure superficielle de la glace à basse température. [Ph.D. thesis, Université de Neuchâtel, 1974.]

Huber, H., and others. 1972. Surface structure of ice studied by proton channeling, [by] H. Huber, C. Jaccard and M. Roulet. Radiation Effects, Vol. 12, Nos. 3-4, p. $24 \mathrm{I}-45$.

Huber, $\mathrm{H}$, and others. 1973. Channeling of $\mathrm{H}^{+}, \mathrm{D}^{+}$and $\mathrm{He}^{+}$in ice: surface disorder and chlorine location, [by] H. Huber, C. Jaccard and M. Roulet. (In Whalley, E., and others, ed. Physics and chemistry of ice: papers presented at the Symposium on the Physics and Chemistry of Ice, held in Ottawa, Canada, $14^{-18}$ August 1972 . Edited by E. Whalley, S. F. Fones, L. W. Gold. Ottawa, Royal Society of Canada, p. 137-39.)

Itoh, N. 1976. Formation of lattice defects by ionizing radiation in alkali halides. Fournal de Physique, Tom. 37, Colloque $\mathrm{C}_{7}$, supplément au No. 12, p. $\mathrm{C}_{7-27} \mathrm{C}_{7-45}$.

Krefft, G. B. I977. Ionization-stimulated annealing effects on displacement damage in magnesium oxide. Journal of Vacuum Science and Technology, Vol. 14, No. 1, p. 533-36.

Krefft, G. B., and others. I975. Effect of ionizing radiation on displacement damage in ion-bombarded single crystal $\alpha-\mathrm{Al}_{2} \mathrm{O}_{3}$ and $\alpha-\mathrm{SiO}_{2}$, by G. B. Krefft, W. Beezhold and E. P. EerNisse. IEEE Transactions on Nuclear Science, Vol. NS-22, No. 6, p. 2247-49.

Matsuo, T., and others. 1973. Relaxational proton ordering in two-dimensional and three-dimensional ices, [by] T. Matsuo, M. Oguni, O. Haida, H. Suga and S. Seki. (In Whalley, E., and others, ed. Physics and chemistry of ice: papers presented at the Symposium on the Physics and Chemistry of Ice, held in Ottawa, Canada, I4-18 August 1972. Edited by E. Whalley, S. F. Jones, L. W. Gold. Ottawa, Royal Society of Canada, p. 272-77.)

Nelson, R. S. 1968 . The observation of atomic collisions in solids. Amsterdam, North-Holland Publishing Co.

Pabst, H. J., and Palmer, D. W. [1975.] Indication for an ionization damage process in light ion irradiation damage in silicon. (In Datz, S., and others, ed. Atomic collisions in solids: proceedings of the fifth International Conference on Atomic Collisions in Solids, held in Gatlinburg, Tennessee, 24-28 September 1973. Edited by S. Datz, B.R. Appleton and C. D. Moak. New York and London, Plenum Press, Vol. 1, p. 141-57.)

Quéré, Y. 1976. On "measurements" of radiation damage by backscattering experiments. Radiation Effects, Vol. 28, Nos. 3-4, p. 253-55.

Unwin, P. N. T., and Muguruma, J. 1972. Electron microscope observations on the defect structure of ice. Physica Status Solidi, A, Vol. 14, No. 1, p. $207-16$.

Varley, J. H. O. 1962. Discussion of some mechanisms of $F$-centre formation in alkali halides. Physics and Chemistry of Solids, Vol. 23, No. 7, p. 985-1005.

Whaling, W. 1958. The energy loss of charged particles in matter. (In Flügge, S., ed. Korpuskeln und Strahlung in Materie. II. Berlin, etc., Springer-Verlag, p. 193-21 7. (Handbuch der Physik, Bd. 34.))

Ziegler, J. F., and Crowder, B. L. 1972. Defining the "random" spectrum as used in the channeling technique of nuclear backscattering. Applied Physics Letters, Vol. 20, No. 4, p. 1 78-79.

\section{DISCUSSION}

O. E. Mogensen: Judged by what is known about radiation damage in other highly irradiated solids (e.g. ionic solids and metals) it seems to be unlikely that you can put up a correct model for the accumulation of the radiation damage based on your very limited amount of data. The yield of displaced oxygen atoms, derived by you to be one per four electronvolts, seems to be much too large when compared to the yields of radicals, etc., normally measured by radiation chemists in most systems. For example, yields of roughly one hydrogen atom and one $\mathrm{OH}^{-}$radical per $100 \mathrm{eV}$ energy loss have been reported for ice. Furthermore, your model does not include the creation of hydrogen atoms (some of which give hydrogen molecules at your temperatures) and $\mathrm{OH}^{-}$radicals (some of which react to form $\mathrm{H}_{2} \mathrm{O}_{2}$ ). The hydrogen molecules might not always diffuse out but aggregate into bubbles of high pressure $\mathrm{H}_{2}$, which might also deform the lattice. 
C. JACGARD: The model is meant only as a simple description of the experimental results. The yield of one displaced oxygen atom per four electronvolts at $-190^{\circ} \mathrm{C}$ is an upper limit, because radicals and misoriented molecules, aggregated or not, can displace several neighbouring molecules; moreover, the processes observed here occur in an already strongly perturbed and weakened lattice, with a lower energy needed to create defects with respect to a normal lattice.

K. ITAGAKI: I have been considering studying the high-temperature side of proton channelling studies but have never had a chance to do so. I am glad that you have done it. One thing which bothers me is that the thickness of the disturbed layer at $-10^{\circ} \mathrm{C}$ is so very large. My results on groove-decay measurements and theoretical analysis of the groove decay due to the presence of a liquid layer indicated that no liquid layer exists at $-10^{\circ} \mathrm{C}$. May $\mathrm{I}$ assume that your liquid (quasi-liquid) layer is not really the liquid layer?

JAGCARD: Our measurements indicate only that oxygen nuclei are displaced by at least $0.2-0.3 \AA$ from their normal lattice position, and they do not imply that the structure is quasi-liquid. Such an effect could be produced by large amplitude vibrations, due to softmode surface phonons, for example.

J. Perez: Do you not think that the maximum you have shown on the curve $\chi$ versus dose, is related to what is called the "peaking effect" by those who are studying radiation damage in metals?

JACCARD: No. "Flux peaking" does not occur near the surface (the region we are concerned with).

M. ElDRUP: Do you not think, even though you use much higher doses than we have done in our positron-annihilation investigations of vacancies, that your lower damage rate above about $-180^{\circ} \mathrm{C}$ than below this temperature has to do with annealing at the higher temperatures as a result of vacancy migration?

JAGGARD: Yes. The vacancy migration (by thermal activation) above $-180^{\circ} \mathrm{C}$ should prevent damage formation. Below $-180^{\circ} \mathrm{C}$, they might move as a result of the stress field created by the disorder, but independent of the temperature. 